\title{
FMCW-Radar-Based Electronic Walking Cane for Blind Pedestrians
}

\author{
Davood Siyar, Hadi Aliakbarian, Senior Member, IEEE \\ Wireless Terminals Measurements Laboratory (WiTeM), KN Toosi University of \\ Technology, Tehran, Iran.
}

\section{1- Introduction}

Radars are sensors which determine relative range, velocity or angle of targets. Advanced radars such as SARs and GPRs are able to capture high resolution photos from intended object or area [1]. In other words, functionality of radar is similar to functionality of eye. Therefore, we came to the novel idea of a FMCW radar which lets blind people see the surroundings by alerting the danger of holes or steps in their walking path. This device is a good complement for walking canes.

Recent development in solid-state devices increases the use of radars in our daily life. Ellis has proposed an intelligent walking cane that employs a radar to detect moving obstacles such as automobile, truck, motorcycle, etc [2]. Some other radar sensors have been designed in mm-wave and microwave frequency band, that aware blind people about their surrounding environment and obstacles such as wall [3]. Unlike our work, both of these devices are not able to aware blind people about possible holes, steps, or irregularities in their walking path.

As shown in Fig.1, the device consists of a low cost FMCW transceiver and two high gain wearable antennas for transmit and receive. The radar, which is design by KNRadar, can detect holes and steps with high accuracy by comparing detected range at earlier PRF with weighted average of detected ranges at previous PRFs.

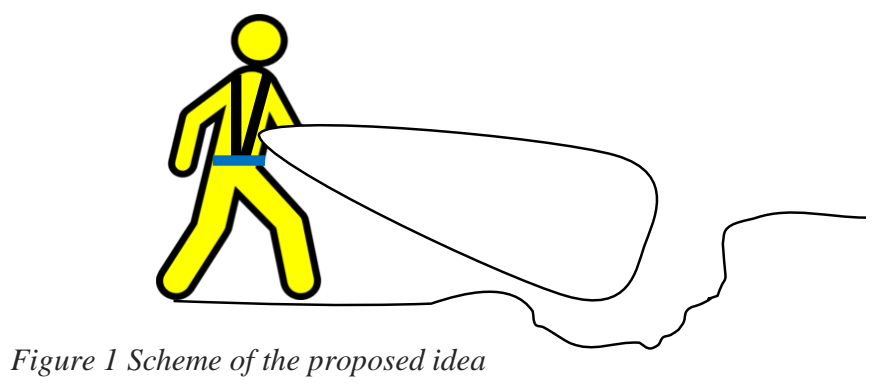

The proposed device will be mounted same as suspenders. Systematic specification of the device, transceiver architecture, antenna type, educational contents and bill of materials is proposed in the following sections.

\section{2- Systematic Specifications}

Systematic specifications of radar and antennas are listed in Table 1. Due to frequency band limitation and to lower its costs, the operating frequency of radar is chosen between 
$2.4 \mathrm{GHz}$ and $2.48 \mathrm{GHz}$ (ISM band). Therefore, the range resolution of the radar will be about $2 \mathrm{~m}$. In order to detect single target, the antenna should illuminate only one range cell. Thus, the antenna's beam width should be less than $15^{\circ}$. The range accuracy is directly related to the sampling frequency. $1 \mathrm{Mbps}$ sampling rate will pass this requirement.

Table 1 Systematic Specifications of RADAR and antennas

\begin{tabular}{|c|c|}
\hline \multicolumn{2}{|c|}{ Specification RADAR } \\
\hline Operating Frequency & $2.4 \mathrm{GHz}$ to $2.5 \mathrm{GHz}$ (ISM \\
\hline Bandwidth & $100 \mathrm{MHz}$ \\
\hline TX power & $20 \mathrm{dBm}$ \\
\hline Sampling frequency & $1 \mathrm{Mbps}$ \\
\hline Range resolution & $1.5 \mathrm{~m}$ \\
\hline Range accuracy Antenna & $20 \mathrm{~cm}$ \\
\hline Null to Null beam width & $15^{\circ}$ \\
\hline Elevation angle & $-30^{\circ}$ \\
\hline
\end{tabular}

\section{3- Transceiver Architecture}

The radar will be implemented with a coherent transceiver based on stretch processing technique [4]. As shown in Fig.2 the transmitter block consists of a low cost and highly linear PLL based FMCW signal generator and an amplifier. Sample of transmitted signal is applied to the receiver mixer as LO. The back scattered wave is applied to the mixer as RF input. Then the baseband signal is constructed from mixing product of the LO and RF. The baseband signal frequency is proportional to range of the target. Therefore, by using a Fourier transform (FFT) and some filtering, the target's range will be detected. This process is performed by the processor unit. We will use a cortex M7 ARM processor as core of processor unit.

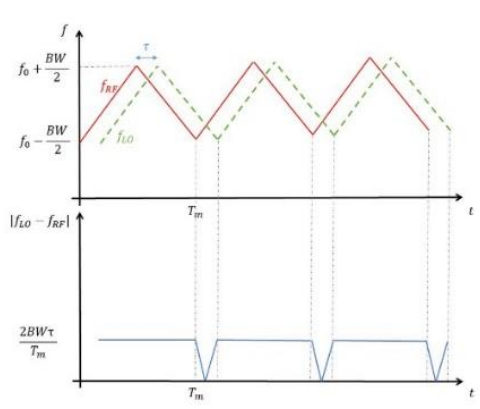

\section{4- Antenna}

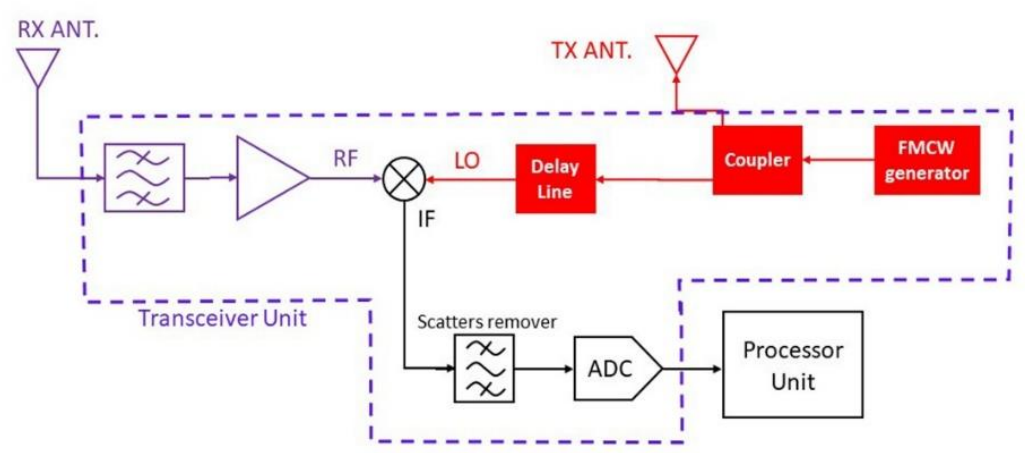

Figure 2 Transceiver architecture

TX and RX antennas are key elements of this device. In order to achieve systematic requirements and ease of use, a wearable series fed antenna array is proposed. This antenna has a tight beam in the desired direction and it can be fabricated on a cotton shoulder strap belt. 


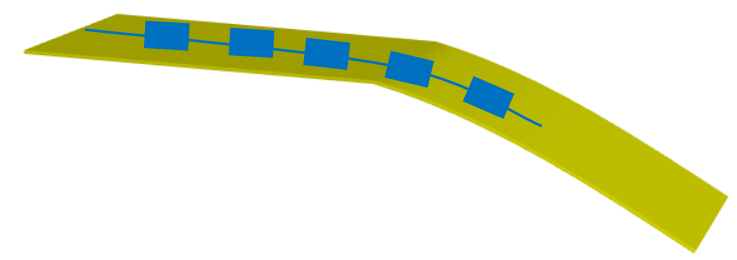

Figure 3 Wearable series fed antenna array structure which is mounted as a suspender

\section{5- Educational Contents}

The proposed device can easily be used for educational purposes not only to study the FMCW radar concepts but also the radiation properties of antennas. Interested students can observe the effect of sweep time, bandwidth and sampling frequency on the range resolution and accuracy by changing them. In addition, they can investigate the effect of antenna side lobes and beamwidth on target detection.

\section{6- Bill of Materials}

\begin{tabular}{|c|c|c|}
\hline No. & Items & $\begin{array}{l}\text { Approximated price } \\
(\$)\end{array}$ \\
\hline 1 & $\begin{array}{l}\text { EVAL-ADF } 4159 \\
\text { FMCW Unit (PLL, VCO, TCXO, MCU, PCB and ...) }\end{array}$ & 200 \\
\hline 2 & $\begin{array}{l}\text { Transceiver Unit (LNA, mixer, filters, amplifier, } \\
\text { coupler, PC-board and ...) }\end{array}$ & 250 \\
\hline 3 & Processor Unit (IF amplifier, ADC, MCU, PC- board) & 360 \\
\hline 4 & Coaxial cable and connectors & 50 \\
\hline 5 & TX and RX antennas & 80 \\
\hline 6 & Total & 940 \\
\hline
\end{tabular}

\section{7- References}

[1] Curlander, J.C. and McDonough, R.N., 1991. Synthetic aperture radar (Vol. 11). Wiley, New York.

[2] Ellis, C.G., Ellis and Christ G., 1999. Intelligent walking stick. U.S. Patent 5,973,618.

[3] Kiuru, T., Metso, M., Utriainen, M., Metsävainio, K., Jauhonen, H.M., Rajala, R., Savenius, R., Ström, M., Jylhä, T.N., Juntunen, R. and Sylberg, J., 2018. Assistive device for orientation and mobility of the visually impaired based on millimeter wave radar technology-Clinical investigation results. Cogent Engineering, 5(1), p.1450322.

[4] M. Skolnik, Radar Handbook. New York: McGraw-Hill, 1990. 